\title{
Artistic Expression of Traditional Chinese Painting
}

\author{
Wang Yujing \\ Department of Science and Engineering, Weinan Normal University, Weinan, Shanxi, China, 714099
}

Keywords: Chinese Painting History, Traditional Chinese Painting Mood, Expression Technique

\begin{abstract}
The Chinese culture is profound, especially Chinese traditional paintings, which is even the representative essence of Chinese culture. Different from western painting, traditional Chinese painting has a long history admired by the descendants. It pursues the internal manifestations while pursuing the similar appearance, and it profoundly reflects the "essence, spirit and god" of the ancients. A good Chinese painting, whether it is full of gorgeous colors, monotonous or seemingly arbitrary, can show the creators' thoughts and even show the times. This paper mainly introduces the historical changes of traditional Chinese painting and the way of expression of its artistic conception.
\end{abstract}

\section{Introduction}

Traditional Chinese painting usually use Chinese brush as a tool, and it draws the ink, paint on rice paper or silk. The main body of Chinese painting takes birds and flowers, landscapes and figures as the main body. The author reflects the society and folk customs, and expresses his views on the world or the love of landscapes. Initially, traditional Chinese painting was usually composed of ordinary lines, simple forming and single-color, so that a few can complete a creation. With the development of humanities, traditional Chinese painting has gradually become an orthodox art, and a simple creation which appears to be arbitrary in time may also be accomplished through repeated elaboration. Chinese painting has realistic and freehand points, and are mostly freehand or combination of the actual situation.

\section{The Historical Changes of Chinese Painting}

The Chinese culture is broad and profound in the past 5,000 years. Chinese painting is an integral part of Chinese culture, and is an indispensable gem. Since the Han Dynasty, Chinese painting has gradually become popular. As the saying goes: "The vitality of the country are all in the customs." At the first nearly 40 years without the use of criminal law of the Han Dynasty, the war continued, and folk customs are popular extravagance. Because the state was busy with the war and neglected the decline of the folk customs, and most of the traditional Chinese paintings were in a doldrums and extravagant style. Later, after the national unification and the success of Wenjing's rule, with the prosperity of the country, the folk style of the Han Dynasty was cured, and the traditional Chinese painting showed a positive and beautiful style. However, even then, the traditional Chinese painting was only in the pursuit of the shape, after all, the technology and materials at that time would have been difficult to create further [1]. Later, Gu Kaizhi, a famous painter in the Eastern Jin Dynasty, created "Female History Proverbs" and "Luoyang Fu Tu" to introduce the new generation of traditional Chinese painting to the new heights of history. His paintings are beautiful and lifelike, and every action is very vivid, which could blind everyone. His vivid works promoted the pursuit of the traditional Chinese painting from shape to spirit. However, the turning point in the style of Chinese painting was the end of the Tang Dynasty, and most of the paintings made by the literati and painters were no longer the rigidity before, but more the feminine side. After entering the Yuan Dynasty, due to the development of technology and the popularity of papermaking, most people have used rice paper to replace the previous silk. The change of such a carrier may seem in significant, in fact, it greatly promoted the development of traditional Chinese painting. Because of the popularity of paper makes paper cheaper, and its production is simple, and 
silk is relative more expensive. In this way, the change of traditional Chinese painting makes the spread of traditional Chinese painting. Even children can complete a "painting", which excavated even more talents. It is also from this moment that Chinese painting has a qualitative over flight. After the Ming and Qing dynasties, most of the traditional Chinese paintings were landscape paintings. The poet, through painting, presented the magnificent beauty of the mountains on paper and also expressed his own multiple emotions.

\section{The Embodiment of Artistic Conception in Traditional Chinese Painting}

\subsection{The development of artistic conception}

Artistic conception is a long aesthetic tradition in Chinese history. It is a unique understanding of the art aesthetic by the literati of the Chinese nation. It sent many tactics and concepts together to the landscape. It also paves the way for the development of the postmodern aesthetic theory, and it laid the foundation. At first, as early as the pre-Qin period, the ancients had the aesthetic sprouting of poetry and prose, and later, the "contention of a hundred schools of thought" in the Spring and Autumn Period had a philosophical reflection on the aesthetic conception. Just as the prosperity of the later Han Dynasty and the inheritance of culture enabled the ancients to pin their spiritual ideas onto actual objects, and the real artistic conception was born. After that, "mood" got particularly development in the Tang and Song Dynasties.

\subsection{The peaks of the use of artistic conception - the scene blend}

Since the Sui Dynasty, the landscape paintings have gradually been taken seriously. More and more literati loved the landscapes and created the specific atmosphere through landscape painting, which made people feel the infinite mood. They are inspired by the beauty of rivers and lakes, not only retaining the beautiful and leisurely scenery on paper, but also expressing their feelings through this lifelike scenery [2]. Just as Wang Guowei, a masters of ancient Chinese studies, he believes that the artistic conception is composed of two parts: the "Scene" and the "Passion". From the surface, we can see the scene and understand it before we can comprehend the situation. Especially in the Song Dynasty, the artistic conception of Chinese painting was vividly demonstrated. At that time, the Song dynasty respected literature and people lived in a prosperous life. Under the foundation of Tang poetry, Chinese painting was even more innovative in Song dynasty. In addition to its literary prosperity, all of the writers in the Song Dynasty also displayed techniques of lyrical things in lyric writing in the process of painting. They combined the words and paintings and pursued the realm of "painting in poetry and poetry in painting". As a result, the combination of poetry and painting jointly promoted the peak of Song culture. For example, Huang Ting-jian's "landscape painting", and he was influenced by Su Shi et al. He was amazed at the country between the vast landscapes, and also expressed his ambitions through the painting. Another example is Zheng Xie in the Qing Dynasty. His "Bamboo and Stone" not only depicted the tenacity of bamboo vividly, but also combined himself to express his perseverance and hard work in the face of great frustration. Scholars travel between landscapes, and they can understand the profound meaning of many lives. Or, they can also have the feeling of hair through small trees and grass in home. The literati drew their seeing and hearing on the language of painting, , and they manifested the beauty directly in order to create a contemplative work of art which can be used by later generations. Or they can feel the beauty of landscapes and understand the author's hidden mood through their imaginative. They neither bounded to write in the text, nor did travel beyond exquisite seen. The landscape in the painting is no longer an ordinary object. It is alive and dexterous in the painting. Bamboo in the cold wind of fortitude does not fall, and is stubborn. Water is flowing in the spring breeze, breaking the ice sheet, and sinking into the sea, soft but without loss of will. Mountain, years seem to not be able to stay in it under the traces, and it is tall and stalwart but it is not impossible to be consummated. In this way, the painting is mapped by the author to the nature and emotions of the person. It has personality, mental status and anthropomorphic scenery, and it incorporates the author's thought of being or not. The artistic conception in the ideological 
painting needs more careful comprehension and can only comprehend the good intentions of the author. This is the true blend of scenes.

\subsection{The expression of the postmodern Chinese painting mood}

With the accumulation of history and culture, the inheritance of Chinese painting techniques and the development of science and technology, the painting forms of traditional Chinese painting are also varied. Nowadays, traditional Chinese painting is usually finished with colored ink. Ink is one of the four treasures of Chinese literature. It can be adjusted into a variety of textures, such as wet ink, dry ink, thick ink and light ink. These are from the original ink water allocation, or are distinguished through the author's writing skills. As a result, the priorities, pen material and ink texture have become the key factors affecting the mood of Chinese painting, and are the backbone and flesh of the traditional Chinese painting. Light, flow clouds in the water on the canvas, make the painting very smart, and can show the soft, ingenuity, and more for small flowers and birds. Heavy, mention pen sonorous and powerful, and deepen its impression to the audience, mostly magnificent scene or majestic mountains and rivers. Among them, the combination of static and dynamic is important. Static, splashing ink landscape creates a quiet and peaceful atmosphere. Moving, slender strokes depicts the flow of rivers and fine breeze in the painting, which makes the landscape is no longer monotonous, although there is no lush flowers, but still angry, and more subtle. In the past, Chinese paintings mostly represented literati painting. Despite the marvelous artistic conception, there was still the bondage of feudalism. Modern Chinese painting, such as Huang Binhong, the Chinese traditional painting artist, draws on the essence of many of great masters and removes some of the shortcomings. He is no longer restricted to ordinary painting, and he comprehends a set of sensory laws from his paintings and finds out the essence of life and explores its meaning. His painting is no longer the first thing he saw. Each painting has its own rules. From his subtle brushwork, you can understand his unique insights. Through simple strokes and even sketches, he expressed his own satirical ideas, which seem impassable and purposeful, but all of the emotions he wanted to express are all fed back into the painting.

\section{The Performance of Artistic Practices}

\subsection{Combination of virtuality and reality}

In the Chinese painting, the two and the artistic conception are inseparable, and the three are closely linked, which is one of the most commonly used techniques. The creator will paint what one sees and hears through painting language on paper, and this is true. And he learned from the essence of what one sees and hears is in fact the paper shown, but it is false [3]. "Reality" shows the creators of painting skills, careful observation, the use of pen and paper and pen weight. The "real" performance can be fully replicated seeing. Paying attention to the shape of the spirit can also show different, fantastic and amazing. But in any case, it needs to show the skills and techniques of painting. Improving the "reality" can help the audience experience the "empty" and understand the artistic conception of the painting. "Virtual" is the cultural content, and people cannot get in the picture with the naked eye. It is through the "real", making the audience to understand the culture and life experience of the creator, or even understanding the artist's temperament just from a picture. they can more deeply understand its unique artistic conception. It can be seen that the combination of virtual and real is an important way of expression. It has a long history and plays an important role in the development of Chinese painting, and it can improve the expressive power of the creator.

\subsection{Space composition and writing skills}

In the creation of Chinese painting, the line is the most important component, and it is the basic creation technique of the expression of the Chinese painting conception. The creator, through the use of the line, divides the layout of the whole painting and outlines different forms. In fact, strokes seem random, it is the carefully pondering results of the creator. The lines are flexible to use to depict vivid landscapes, flowers, birds and characters. It is quite similar to the shape, and can make 
the audience through these seemingly arbitrary strokes to comprehend the artistic conception. In color, in addition to pure black and white, some Chinese painting art creation use large thick and heavy in color. The inks make the picture becomes very powerful, so that the audience gifted with an extraordinary retentive memory away.

\subsection{The combination of poetry and painting}

Since ancient times, Chinese art is always with the combination of poetry and painting style presented in front of the world. A good painting often involves poets for their painting, so that the painting has more cultural connotation, and also enables the painter's inner feelings to be placed in paintings, forming a unity of poetry, painting and emotion. In the same way, a famous poem is often painted by a painter, which will deepen the meaning of the poem itself and help the reader to understand the poetry more easily. And this is Painting-in-poetry, Poetry-in-painting, and it is a unique form of Chinese classical art. With the development of science and technology, the copying of traditional Chinese painting is far less realistic than that captured by the camera. Therefore, the creation of traditional Chinese painting focuses more on the feelings behind the objective scenery. For the same mountain scenery, different people have different views. Some people will see soaring peaks, while others will see the mountains surrounded by repeatedly clouds, and others will see ambition. The Chinese painting should describe the scenery by unique style of writing and coloring, and embody the unique emotion of the family in the painting of the scene. For example, in Yuan Mu's Poems "see", the boy is to want to sing, and suddenly, there is a closed set and the idea of catching cicada. In the match painting of "see", if the emotion of the poem is expressed, the painter should carefully handle the facial expression of the shepherd boy. In traditional Chinese painting art, the combination of poetry and painting is an important artistic form, which is for the painter to have high aesthetic qualities and literary heritage. Only better educated, one can be able to use a brush to reproduce the poet created out of the picture. A man who has good painting ability, will continue to imagine poetry imagery, and then creates a dreamlike aesthetic mood.

\section{Conclusions}

With the economic globalization and the continuous economic development in our country, the integration of our country's culture and the world's culture has been brought about. The exchange between our country and the rest of the world has also kept pace with the times. Chinese traditional painting is no longer the art treasure of Chinese traditional culture, but also the world's art treasure. With the change of history, science and technology are constantly innovating and humanities are constantly improving. We should make innovations even more while developing traditional culture.

\section{References}

[1] Xu Li. Seeking the Same Image - On the Image of Chinese Painting [J]. Art Kam, 2016, (1): 190.

[2] Huang Qiusha. Explore artistic expression of traditional Chinese painting techniques [J]. Young Writer, 2015, (30): 171.

[3] Chen Ling. Changes in artistic expression of Chinese painting art [J] .Art Education Research, 2015, (10): 15 